\title{
Differential Postnatal Development of Catecholamine and Serotonin Inputs to Identified Neurons in Prefrontal Cortex of Rhesus Monkey
}

\author{
Evelyn K. Lambe, Leonid S. Krimer, and Patricia S. Goldman-Rakic \\ Section of Neurobiology, Yale University School of Medicine, New Haven, Connecticut 06520
}

\begin{abstract}
The monoaminergic innervation of cerebral cortex has long been implicated in its development. Methods now exist to examine catecholamine and serotonin inputs to identified neurons in the cerebral cortex. We have quantified such inputs on pyramidal and nonpyramidal cells in prefrontal cortex of rhesus monkeys ranging in age from 2 weeks to 10 years. Individual layer III neurons were filled with Lucifer yellow and doubleimmunostained with axons containing either tyrosine hydroxylase $(\mathrm{TH})$ or 5 -hydroxytryptamine $(5-\mathrm{HT})$. The filled cells were reconstructed, and putative appositions between the axons and dendritic spines and shafts were quantified at high magnification using light microscopy.

The density of catecholamine appositions on pyramidal neurons matures slowly, reaching only half the adult level by 6 months of age and thereafter rising gradually to adult levels by 2
\end{abstract}

years of age. By contrast, the density of serotonin appositions on pyramidal cells reaches the adult level before the second week after birth. The average adult pyramidal neuron in layer III of area $9 \mathrm{~m}$ receives three times stronger input from catecholaminergic than from serotoninergic axons. The overall density of both inputs to interneurons does not appear to change during postnatal development. Selective changes in the TH innervation of pyramidal cells against a backdrop of constant TH innervation of interneurons suggest that the balance between excitation and inhibition may change developmentally in the prefrontal cortex. By contrast, 5-HT innervation of both types of neurons remains relatively constant over the age range studied.

Key words: tyrosine hydroxylase; dopamine; serotonin; 5-hydroxytryptamine; pyramidal neuron; interneuron; rhesus monkey; nonhuman primate; prefrontal cortex
Monoaminergic systems of the brain modulate excitatory transmission in cortical circuits that are critical for normal adult function of prefrontal cortex (Williams and Goldman-Rakic, 1995; Vollenweider et al., 1998). The same neurotransmitters have been implicated directly and indirectly in several aspects of neurodevelopment (Mattson, 1988; Levitt et al., 1997), in the pathophysiology of schizophrenia (Lieberman, 1999), and in the psychotomimetic effects of certain hallucinogens (Breier, 1995; Farber et al., 1999; Gouzoulis-Mayfrank et al., 1999). There are timing similarities among the attainment of peak working memory performance (Diamond and Goldman-Rakic, 1989), the typical age of onset of schizophrenia (Lieberman, 1999), and the age at which certain drugs begin to trigger psychosis (Farber et al., 1999). These developmental parallels suggest that a detailed understanding of the postnatal changes in monoaminergic input to cortical neurons may shed light on the changes in circuitry needed for mature working memory performance, as well as on how this circuitry may become disrupted in psychosis.

Monoamines have been extensively studied during embryonic development (Lauder and Bloom, 1974; Coyle and Molliver, 1977; Buznikov, 1984; Mattson, 1988; Verney et al., 1993; Levitt, 1997), yet relatively few studies in vitro have addressed postnatal changes in monoaminergic innervation of frontal cortex. Over the prepubertal period, serotonin and dopamine levels appear to fluctuate before rising to adult levels at puberty (Goldman-Rakic and Brown, 1982). However, differences exist between these two neurotransmitters. From birth to adulthood, there is a protracted and dramatic increase in the synthetic capacity for dopamine, whereas that for serotonin stays at a constant low level (Goldman-Rakic and Brown, 1982). Furthermore, the length of axons that contain tyrosine hydroxylase $(\mathrm{TH})$, an enzyme critical for the production of dopamine, continues to increase until puberty (Rosenberg and Lewis, 1995). In addition, adult TH density in area 9 of frontal

\footnotetext{
Received July 11, 2000; revised Aug. 31, 2000; accepted Sept. 12, 2000.

We thank Terri Beattie and Heather Findlay for expert assistance with animal care. Correspondence should be addressed to Patricia Goldman-Rakic, Section of Neurobiology, Yale University School of Medicine, P.O. Box 208001, New Haven, CT 06520-8001. E-mail: patricia.goldman-rakic@yale.edu.

Copyright (C) 2000 Society for Neuroscience $0270-6474 / 00 / 208780-08 \$ 15.00 / 0$
}

cortex is much greater than that for 5-hydroxytryptamine (5-HT) (Lewis et al., 1992).

These differences in axonal density during postnatal development raise the question of how they affect individual neurons in prefrontal cortex. Anatomical work in the adult has shown a predominance of $\mathrm{TH}$ innervation onto pyramidal cells relative to interneurons (Krimer et al., 1997). Functional studies in the adult have shown that dopamine modulates the ability of prefrontal neurons to maintain activity during the delay period of working memory tasks (Sawaguchi et al., 1990; Williams and GoldmanRakic, 1995). In view of pronounced differences in working memory ability across postnatal development (Diamond and GoldmanRakic, 1989), understanding of the developmental changes in monoaminergic innervation of single neurons in frontal cortex may provide insight into the anatomical underpinning of cognitive maturation.

In summary, this study presents findings using infrared differential interference contrast (IR-DIC) videomicroscopy to fill selected individual neurons in rhesus monkeys, followed by doubleimmunostaining and quantification of contacts between monoaminergic axons and labeled cortical neurons. The pattern of $\mathrm{TH}$ and 5-HT innervation to identified pyramidal cells and interneurons shows changes over the first 10 postnatal years. The relevance of these findings in regard to changes in dopamine-dependent properties of prefrontal function, including its vulnerability during adolescence to schizophrenia and ketamine-induced psychosis, is discussed.

\section{MATERIALS AND METHODS}

Tissue preparation. Twelve monkeys between the ages of 2 weeks and 10 years were administered ketamine $(5-10 \mathrm{mg} / \mathrm{kg})$ and atropine $(0.2 \mathrm{mg} / \mathrm{kg})$ and placed under deep surgical anesthesia with sodium pentobarbitol (100 $\mathrm{mg} / \mathrm{kg}$ ). They were then perfused transcardially with a solution of $4 \%$ paraformaldehyde, $15 \%$ picric acid, and $0.2 \%$ gluteraldehyde in $0.1 \mathrm{M}$ phosphate buffer (PB) for 4-7 min, depending on the age and the size of the animal. The ages of the monkeys are shown in Tables 1 and 2. Two animals were included at the following ages: 2 weeks, 2 months, and 2 years. Tissue blocks from dorsomedial area 9 in the left hemisphere were excised and sectioned with a microtome into $400 \mu \mathrm{m}$ slices. These slices were maintained in ice-cold PB until injection.

Injection of fluorescent dye. Layers within the cortex were visualized 


\begin{tabular}{|c|c|c|c|c|}
\hline Age & Axon type & $\begin{array}{l}\text { Density (appositions/ } \\
100 \mu \mathrm{m})\end{array}$ & $\begin{array}{l}\text { Total } \\
\text { appositions }\end{array}$ & $\begin{array}{l}\text { Neurons } \\
\text { analyzed }\end{array}$ \\
\hline \multirow[t]{2}{*}{2 weeks } & TH & $0.27 \pm 0.09$ & $13 \pm 5$ & 8 \\
\hline & 5-HT & $0.17 \pm 0.07$ & $8 \pm 3$ & 4 \\
\hline \multirow[t]{2}{*}{2 months } & $\mathrm{TH}$ & $0.34 \pm 0.05$ & $14 \pm 3$ & 6 \\
\hline & 5-HT & $0.27 \pm 0.08$ & $18 \pm 4$ & 3 \\
\hline \multirow[t]{2}{*}{6 months } & $\mathrm{TH}$ & $0.43 \pm 0.10$ & $28 \pm 9$ & 4 \\
\hline & 5-HT & $0.22 \pm 0.08$ & $14 \pm 1$ & 2 \\
\hline \multirow[t]{2}{*}{1 year } & $\mathrm{TH}$ & $0.50 \pm 0.09$ & $37 \pm 4$ & 4 \\
\hline & 5-HT & $0.26 \pm 0.02$ & $16 \pm 2$ & 2 \\
\hline \multirow[t]{2}{*}{2 years } & $\mathrm{TH}$ & $0.70 \pm 0.11$ & $60 \pm 17$ & 4 \\
\hline & 5-HT & $0.21 \pm 0.07$ & $19 \pm 4$ & 3 \\
\hline 3 years & $\mathrm{TH}$ & $0.72 \pm 0.14$ & $58 \pm 13$ & 5 \\
\hline 5 years & 5-HT & $0.27 \pm 0.01$ & $23 \pm 1$ & 2 \\
\hline 6 years & TH & $0.79 \pm 0.14$ & $61 \pm 7$ & 4 \\
\hline 10 years & TH & $0.80 \pm 0.04$ & $69 \pm 17$ & 2 \\
\hline
\end{tabular}

\begin{tabular}{|c|c|c|c|c|}
\hline Age & Axon type & $\begin{array}{l}\text { Density (appositions/ } \\
100 \mu \mathrm{m})\end{array}$ & $\begin{array}{l}\text { Total } \\
\text { appositions }\end{array}$ & $\begin{array}{l}\text { Neurons } \\
\text { analyzed }\end{array}$ \\
\hline \multirow[t]{2}{*}{2 weeks } & $\mathrm{TH}$ & $0.27 \pm 0.20$ & $3 \pm 2$ & 4 \\
\hline & 5-HT & $0.16 \pm 0.04$ & $3 \pm 1$ & 8 \\
\hline \multirow[t]{2}{*}{2 months } & TH & $0.35 \pm 0.23$ & $4 \pm 2$ & 16 \\
\hline & 5-HT & $0.20 \pm 0.05$ & $2 \pm 1$ & 2 \\
\hline \multirow[t]{2}{*}{1 year } & $\mathrm{TH}$ & $0.42 \pm 0.17$ & $5 \pm 3$ & 2 \\
\hline & 5-HT & $0.22 \pm 0.04$ & $4 \pm 3$ & 2 \\
\hline 2 years & 5-HT & $0.18 \pm 0.06$ & $3 \pm 2$ & 5 \\
\hline \multirow[t]{2}{*}{6 years } & $\mathrm{TH}$ & $0.37 \pm 0.21$ & $4 \pm 3$ & 3 \\
\hline & 5-HT & $0.23 \pm 0.07$ & $4 \pm 2$ & 3 \\
\hline 10 years & TH & $0.40 \pm 0.20$ & $5 \pm 5$ & 13 \\
\hline
\end{tabular}

under fluorescent light on a Zeiss Axioskop FS microscope (Oberkochen, Germany) after preincubation of the slice in a $10 \mathrm{~nm}$ solution of 4',6diamidino-2-phenylindole (Sigma, St. Louis, MO) in 0.1 M PB. Pyramidal cells and interneurons in layer III were selected using high-resolution IR-DIC videomicroscopy and injected with a $7.5 \%$ aqueous solution of Lucifer yellow (dilithium salt, Sigma) under visual control.

Layer III of the prefrontal cortex was chosen for this analysis because it is the major recipient of the cortico-cortical connections. Because this circuitry appears to undergo dramatic postnatal changes and possibly to be vulnerable in schizophrenia, it is important to understand its normal pattern of postnatal development. Furthermore, layer III in area 9 has been reported to show particularly dramatic postnatal changes in TH innervation (Rosenberg and Lewis, 1995).

Immunohistochemistry. Slices were processed to visualize the filled cells and to develop either TH or 5-HT axons. Although TH is critical for the synthesis of both dopamine and norepinephrine, previous work suggests that the mouse antibody we used against $\mathrm{TH}$ predominantly labels dopamine-containing axons in monkey cortex (Noack and Lewis, 1989; Akil and Lewis, 1993; Williams and Goldman-Rakic, 1993).

Slices were post-fixed for $4 \mathrm{hr}$ in $4 \%$ paraformaldehyde, resectioned by $40 \mu \mathrm{m}$ using a microslicer (DSK, Dosaka, Japan), and blocked for $3 \mathrm{hr}$ with a solution of $10 \%$ normal goat or donkey serum, $2 \%$ bovine serum albumin, and $0.5 \%$ Triton X-100. For TH immunohistochemistry, the sections were incubated with a mouse antibody to $\mathrm{TH}$ (Chemicon, Temecula CA), together with a biotin-conjugated rabbit antibody to Lucifer yellow (Molecular Probes, Eugene, OR), for $48 \mathrm{hr}$ at $4^{\circ} \mathrm{C}$. For 5-HT immunocytochemistry, the sections were first incubated with a rabbit antibody to 5-HT (Incstar, Stillwater, MN) for $48 \mathrm{hr}$ at $4^{\circ} \mathrm{C}$, then incubated with a goat anti-rabbit Fab fragment (Jackson, West Grove PA) for $24 \mathrm{hr}$ at $4^{\circ} \mathrm{C}$, and with a biotin-conjugated rabbit antibody to Lucifer yellow for $24 \mathrm{hr}$ at $4^{\circ} \mathrm{C}$.

Sections were placed in an ABC Elite (Vector, Burlingame, CA) solution so that filled neurons could be visualized with a brown chromogen by a reaction between avidin-HRP and 3,3'-diaminobenzidine (DAB). The sections were then incubated for $2 \mathrm{hr}$ at room temperature with the appropriate biotin-conjugated secondary antibody: anti-mouse IgG for $\mathrm{TH}$ or anti-goat IgG for 5 -HT (Vector). They were rinsed with a $0.3 \%$ solution of hydrogen peroxide to remove the remaining peroxidase activity on the labeled neurons. After a second $\mathrm{ABC}$ reaction, the TH or 5-HT axons were visualized with the black chromogen, nickel-intensified DAB. To control for possible variations between immunohistochemical procedures and conditions, sections from different animals were processed together during the same experiment. The sections were dehydrated, using a free floating method described in Krimer et al. (1997) to preserve the $z$-axis dimension (Krimer et al., 1997), and mounted on glass slides. Nissl staining on an adjacent section was used to verify the laminar location of the filled neurons.

Neurolucida software (MicroBrightField, Colchester, VT), in conjunction with an Axioskop Zeiss microscope, was used to trace and measure the dendritic tree of each neuron in three dimensions. Appositions of TH or 5-HT axons to dendritic spines or shafts were marked along the tracing. The TH or 5-HT apposition density (per $100 \mu \mathrm{m}$ ) was calculated for each neuron. Contacts were judged as membrane appositions if no distance appeared between the two structures in any focal plane at $1580 \times$ magnification (Krimer et al., 1997). All immunohistochemistry and Neurolucida tracings were conducted without reference to the age of the subjects.

\section{RESULTS}

Fifty-three pyramidal cells and 58 interneurons were filled with Lucifer yellow dye from 12 monkeys ranging in age from 2 weeks to 10 years. As illustrated in Figures 1-3, filled pyramidal cells and interneurons are stained brown, and either serotonin or TH axons are stained black. Immunostaining for 5-HT and TH was successful at all ages, although greater care and reduced Triton X-100 were required in the handling of tissue from the 2-week-old monkeys. Labeled axons could be followed throughout the depth of the sections. Tissue shrinkage was estimated to be $20 \pm 10 \%$ by measuring several dendrites before and after dehydration. Variation in shrinkage did not correlate with age. Pyramidal cells showed dramatic increases in dendritic length and arborization over the first postnatal year. For example, at 2 weeks, the average dendritic length was $5 \pm 2 \mathrm{~mm}$, and by 1 year it had increased dramatically to $8 \pm 1 \mathrm{~mm}$, as shown in Figure 4 . By contrast, interneurons did not show a significant increase in dendritic length over the age range studied.

Brown-stained pyramidal cells could be followed through several $40 \mu \mathrm{m}$ sections to the terminal endings of their spine-studded apical and basal dendrites. Similarly, interneurons of varying morphologies could be followed through several slides. As can be seen in Figure 1, the black TH axons varied greatly in diameter, and all but the thickest axons exhibited numerous varicosities. A dense band of axons was observed in layers I and II in all the monkeys, in agreement with previous studies (Williams and Goldman-Rakic, 1993). This band was wider in the youngest monkeys, extending into superficial layer III. A sample of fully reconstructed neurons across the age range studied indicated that the density of contacts between TH axons and pyramidal cell dendrites did not differ significantly in the apical or basal dendritic fields (both $0.7 \pm 0.1$ appositions per $100 \mu \mathrm{m}$ dendrite). However, the total density and the appearance of the appositions varied significantly with the age of the monkey. In the adult, the TH axons tended to follow the dendrite that they contacted. In the young monkey, by contrast, there were fewer contacts, and the TH axons making appositions with pyramidal cell dendrites generally intersected at $90^{\circ}$ and did not course along the branches (Fig. $1 C$ ). The majority $(\sim 60 \%)$ of $\mathrm{TH}$ axons contacted a spine rather than the shaft of a pyramidal cell dendrite, as shown in Figure 5.

In the sections stained for 5-HT, shown in Figure 2, the black axons also showed a convoluted pattern and many varicosities. Both fine and thick axons were resolved, as previously described in adult cortex (Wilson et al., 1989). The laminar pattern in area $9 \mathrm{~m}$ of frontal cortex showed a higher-density band in layer I. Passing fibers contacted dendrites, but tended not to follow them for extended distances in both adult and young monkeys (compare Figs. $1 D$ and $2 D$ ). At all ages, few contacts between 5-HT axons and neuronal dendrites were present: $0.2 \pm 0.1$ apposition density. In a sample of fully reconstructed neurons, the apposition density on basal and apical dendrites did not differ significantly. The majority $(\sim 80 \%)$ of 5 -HT axons contacted the shaft rather than a spine on pyramidal cell dendrites, as shown in Figure 5.

The varied size and morphology of filled interneurons suggest 

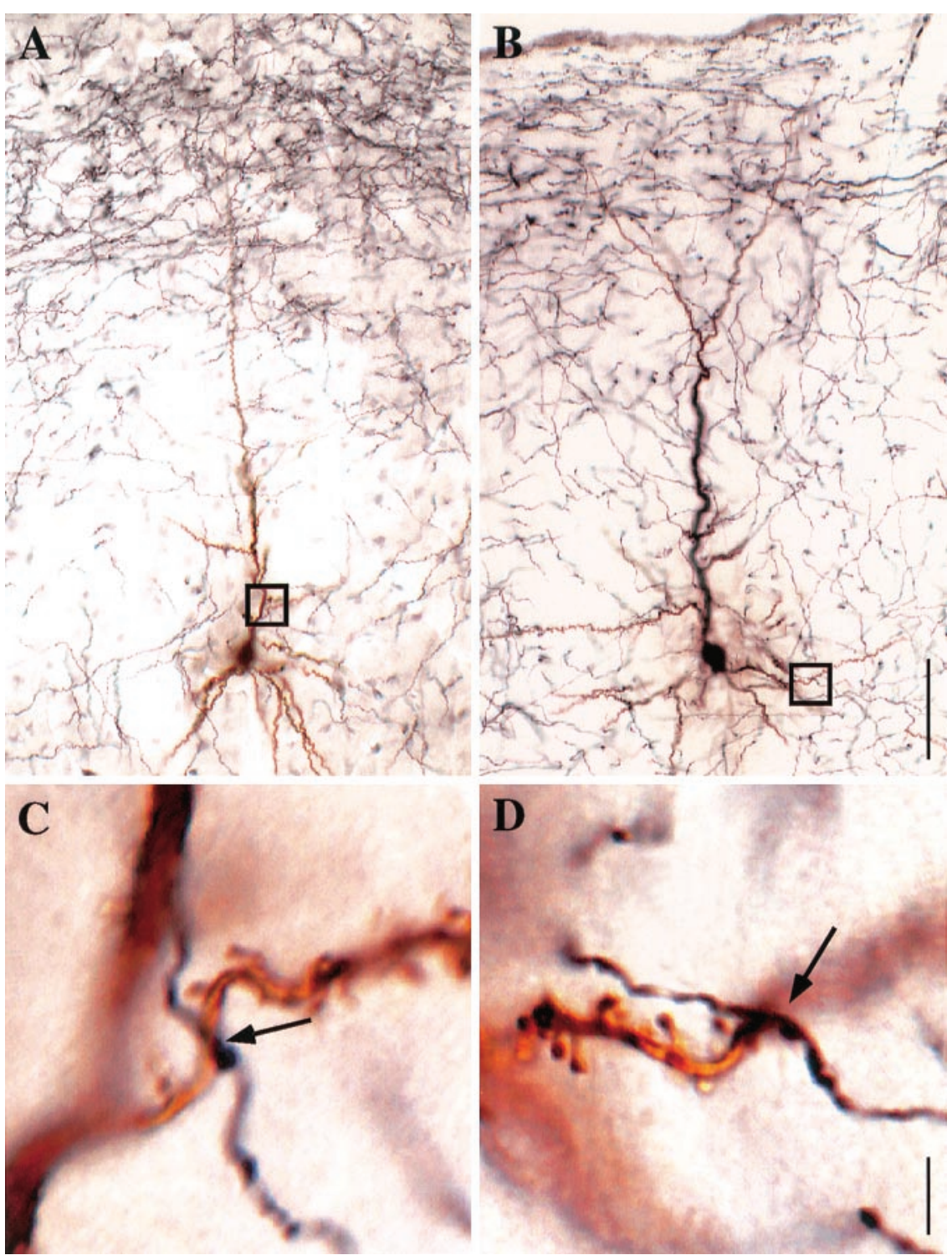

Figure 1. Comparison of pyramidal cell and $\mathrm{TH}$ axon characteristics over the course of postnatal development. $A, B$, Pyramidal neuron 2 weeks after birth $(A)$ and adult neuron $(B)$. Boxed areas are enlarged below. $C, D$, Arrows point to appositions between the $\mathrm{TH}$ axon and a dendritic shaft $(C)$ and TH apposition with dentritic spine $(D)$. Scale bars: $A, B, 100 \mu \mathrm{m} ; C$, $D, 20 \mu \mathrm{m}$.

that many different subtypes were included; two interneurons are shown in Figure 3. The variance in the apposition density of $\mathrm{TH}$ on interneurons was much greater than for pyramidal cells. However, we did not have a sample of sufficient size to assess possible differences in apposition density according to morphological subtype. The TH apposition density on pyramidal cells tripled over the course of postnatal development, as shown in Figure 6. This increase was highly significant $\left(r=0.77, R^{2}=0.60, p=0.0001\right)$, increasing only a small amount from $0.2 \pm 0.1$ to $0.3 \pm 0.1$ appositions per $100 \mu \mathrm{m}$ in the first 2 months after birth, then rising exponentially to $0.7 \pm 0.1$ apposition density by puberty. As indicated on Figure 6, the TH apposition density remained at this high level into adulthood. The number of $\mathrm{TH}$ appositions increased more than five times over the age range studied and, as illustrated by Figure 7, was highly correlated with dendritic length $(r=0.96$, $\left.R^{2}=0.91, p=0.0002\right)$. By contrast, 5-HT apposition density on pyramidal cells remained at a constant low level of $0.2 \pm 0.1$ appositions per $100 \mu \mathrm{m}$ over this same age range. However, low density of 5-HT-immunoreactive axons and small sample size raise the possibility that the methods used were not sensitive enough to detect changes in density. The TH and 5-HT apposition densities on pyramidal cells differ significantly at every age after 2 months $(p=0.01)$.

On interneurons, both $\mathrm{TH}$ and 5-HT apposition density appeared to have reached adult levels by 2 weeks, as illustrated in
Figure 6. The wider variation in apposition density by $\mathrm{TH}$ axons on interneurons suggests that subtypes of nonpyramidal cells may receive differential innervation. The number of $\mathrm{TH}$ appositions did not correlate significantly with interneuron dendritic length.

\section{DISCUSSION}

There is a dramatic and specific increase in the TH innervation of pyramidal cells in layer III of dorsomedial prefrontal cortex in rhesus monkey. This increase appears to occur gradually and monotonically, reaching the highest levels during puberty, and remains undiminished into adulthood. By contrast, TH innervation of interneurons and 5-HT innervation of both interneurons and pyramidal cells remain stable at lower levels over this period of postnatal development. Three-dimensional reconstruction of individual cells showed that adult pyramidal cells in this region receive three times as many contacts from TH axons as from 5-HT axons.

To our knowledge, this is the first study to examine developmental changes in monoamine inputs to single pyramidal cells and interneurons. Although previous work has described postnatal changes in biochemical levels of monoamines (Goldman-Rakic and Brown, 1982) and in elaboration of TH axons (Rosenberg and Lewis, 1995), it is changes at the single neuron level that are perhaps the most relevant to physiology and behavior. Such changes in innervation to single cells can only be assessed at the light microscopic level. Although light microscopy cannot confirm 


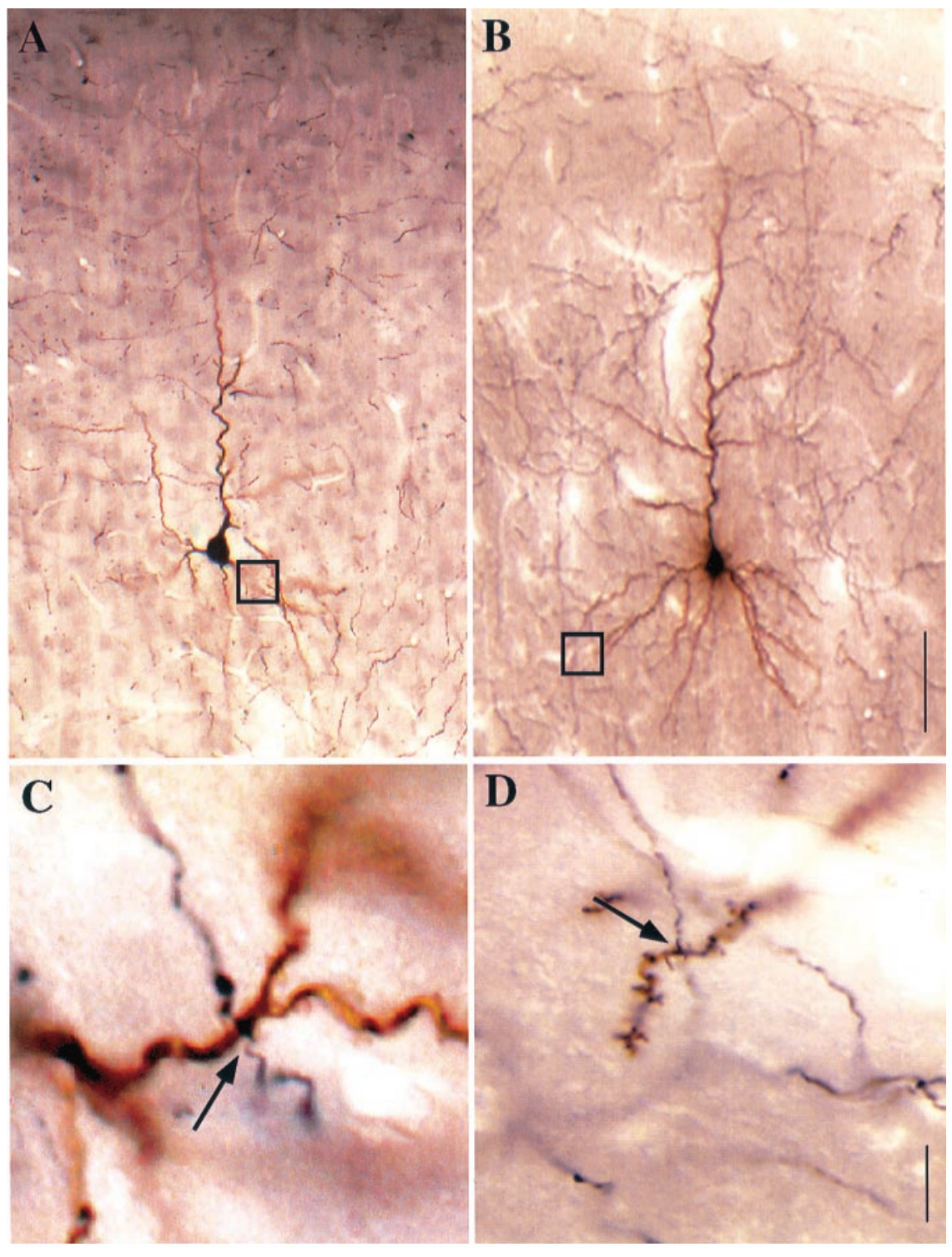

Figure 2. Comparison of pyramidal cell and 5-HT axon characteristics over course of postnatal development. $A, B$, Pyramidal neuron 2 weeks after birth $(A)$ and adult neuron $(B)$. Boxed areas are enlarged below. $C, D$, Arrows point to appositions between 5-HT axon and a dendritic shaft $(C)$ and a dendritic spine $(D)$. Scale bars: $A, B, 100 \mu \mathrm{m} ; C, D, 20 \mu \mathrm{m}$. synaptic contacts, a sample of appositions taken to the electron microscope (EM) level in a previous study using the same methodology revealed that each light level apposition indeed represented one or more synaptic junctions (Krimer et al., 1997).

\section{Postnatal development of TH and 5-HT innervation}

A large body of evidence suggests that monoamines play an important role in both prenatal and postnatal development of cerebral cortex (Coyle and Molliver, 1977; Buznikov, 1984; Mattson, 1988; Kalsbeek et al., 1989, Meier et al., 1991; Levitt, 1997). Dopamine, in particular, has been implicated as critical for the normal arborization of pyramidal cell dendrites (Kalsbeek et al., 1989). Serotonin also appears to play an important role in shaping neuronal circuits by regulating synaptic plasticity and neuronal activity patterns (Chubakov et al., 1986; Gu and Singer, 1995; Cases et al., 1996).

The protracted postnatal increase in the density of dopaminergic inputs to pyramidal cells occurs over a time frame contemporaneous with other developmental changes, including the following: rapid growth of pyramidal cells (Koenderink et al., 1994), a dramatic increase in spine density on these cells (Anderson et al., 1995), the peak and decline in density of asymmetric synapses (Rakic et al., 1986; Bourgeois et al., 1994) and multiple receptor subtypes (Lidow et al., 1991), the slow maturation of delay-period activity in prefrontal neurons, and the emergence of adult levels of competence on working memory tasks (Goldman-Rakic, 1987).
Throughout the passing of these developmental milestones, the density of 5-HT inputs to pyramidal neurons and both the $\mathrm{TH}$ and 5-HT inputs to interneurons remain surprisingly constant.

Our findings are congruent with previous work which showed that $\mathrm{TH}$ axon length and number of varicosities continue to increase until puberty (Rosenberg and Lewis, 1995), as well as with studies showing that adult density $\mathrm{TH}$ in area 9 of the frontal cortex far exceeds that for 5-HT (Lewis et al., 1992). A previous study reported a decrease in $\mathrm{TH}$ axon length and varicosities after puberty (Rosenberg and Lewis, 1995). However, we fail to find such diminution at the level of innervation of single pyramidal cells. Maintenance of a high level of TH apposition density on pyramidal cells over a period of declining TH axons and varicosities suggests loss of nonspecific innervation.

In adult monkey prefrontal cortex, dopamine axon terminals are known to form symmetric contacts with dendritic spines and shafts of pyramidal neurons, as well as with dendrites of local circuit neurons that contain GABA (Smiley and Goldman-Rakic, 1993; Sesack et al., 1998). Sesack and colleagues (1998) showed that TH axons in layer III of monkey frontal cortex preferentially contacted interneurons containing parvalbumin and avoided those containing calretinin (Sesack et al., 1998). The greater variability that we observed in $\mathrm{TH}$ apposition density on interneurons may reflect selective targeting of interneuron subtypes by $\mathrm{TH}$ axons. As a result, it is conceivable that we may have missed a small or subtype- 
Figure 3. $A, B$, Interneurons from 2-year-old monkeys and $\mathrm{TH}(A)$ and 5-HT $(B)$ axons. Boxed areas are enlarged below. $C, D$, Arrows point to appositions between TH axon $(C)$ or 5-HT axon $(D)$ and dendritic shafts. Scale bars: $A, B, 80 \mu \mathrm{m} ; C, D, 20 \mu \mathrm{m}$.
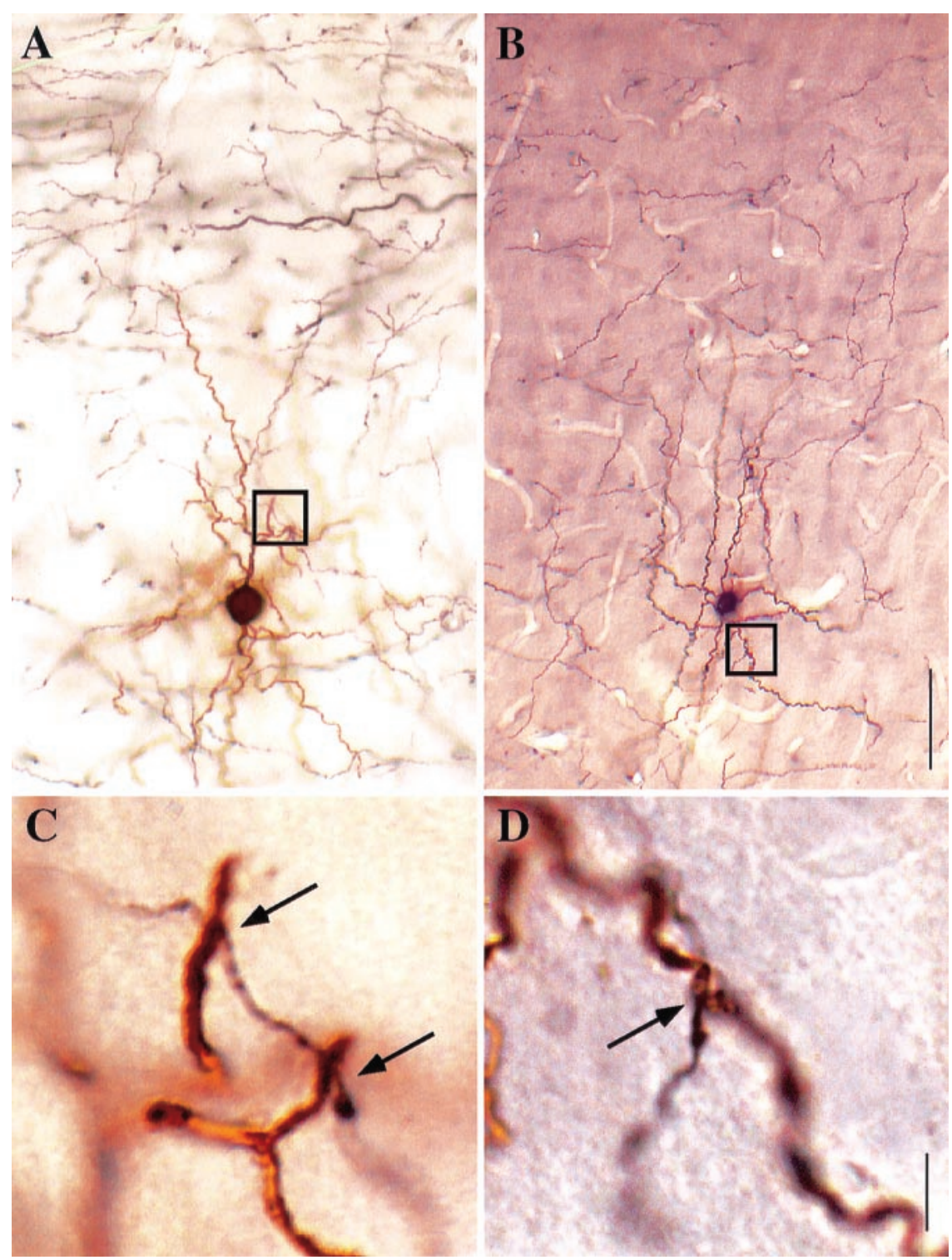

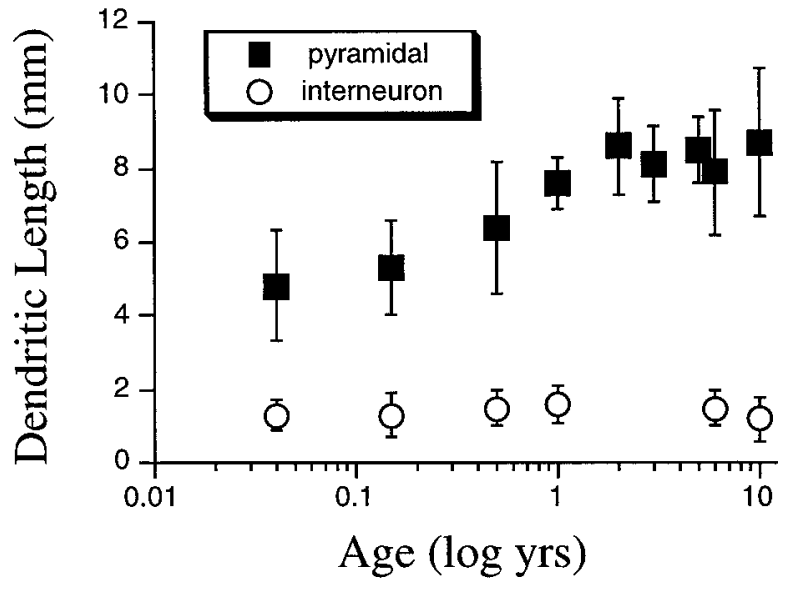

Figure 4. Mean dendritic length of pyramidal neurons and interneurons in layer III of primate prefrontal cortex for each group, plotted against age on a logarithmic scale.

specific change in TH innervation of interneurons. At the EM level, $40-90 \%$ of contacts between $\mathrm{TH}$ and dendrites have morphological features of a symmetric synapse (Descarries et al., 1991; Smiley and Goldman-Rakic, 1993). Indeed, spines of pyramidal neurons in prefrontal cortex are frequently postsynaptic to both a dopamine terminal and an excitatory terminal, allowing for direct dopamine modulation of local glutamate transmission (Goldman-Rakic et al., 1989). This result is further supported by our finding that the majority of $\mathrm{TH}$ appositions on pyramidal neurons contacted dendritic spines.

EM studies in adult rat and primate frontal cortex have shown that 5-HT axon terminals form symmetric contacts with dendritic shafts of pyramidal and nonpyramidal cells (Descarries et al., 1991; Smiley and Goldman-Rakic, 1996). Only 20-30\% of such appositions have been found to have synaptic specialization (Descarries et al., 1991; Smiley and Goldman-Rakic, 1996). Volume transmission of both transmitters and the widespread location of receptors on dendritic arbors of pyramidal and nonpyramidal cells make the existence of nonsynaptic junctional appositions functionally relevant (Zoli and Agnati, 1996). In fact, volume transmission may account for the mismatch between the widespread locations of 5-HT appositions on pyramidal cells and the high concentration of $5-\mathrm{HT}_{2 \mathrm{~A}}$ receptors found on the apical dendrites (Jakab and Goldman-Rakic, 1998). Light-level appositions quantified in this study may represent distances between dendrite and axon of up to $200 \mathrm{~nm}$.

A comprehensive analysis of synaptogenesis in primate prefrontal cortex shows a marked difference over the time course required for asymmetric and symmetric synapses to reach peak levels (Bour- 


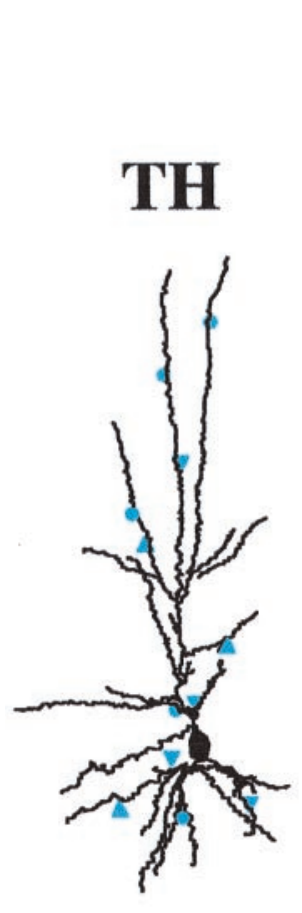

2 week
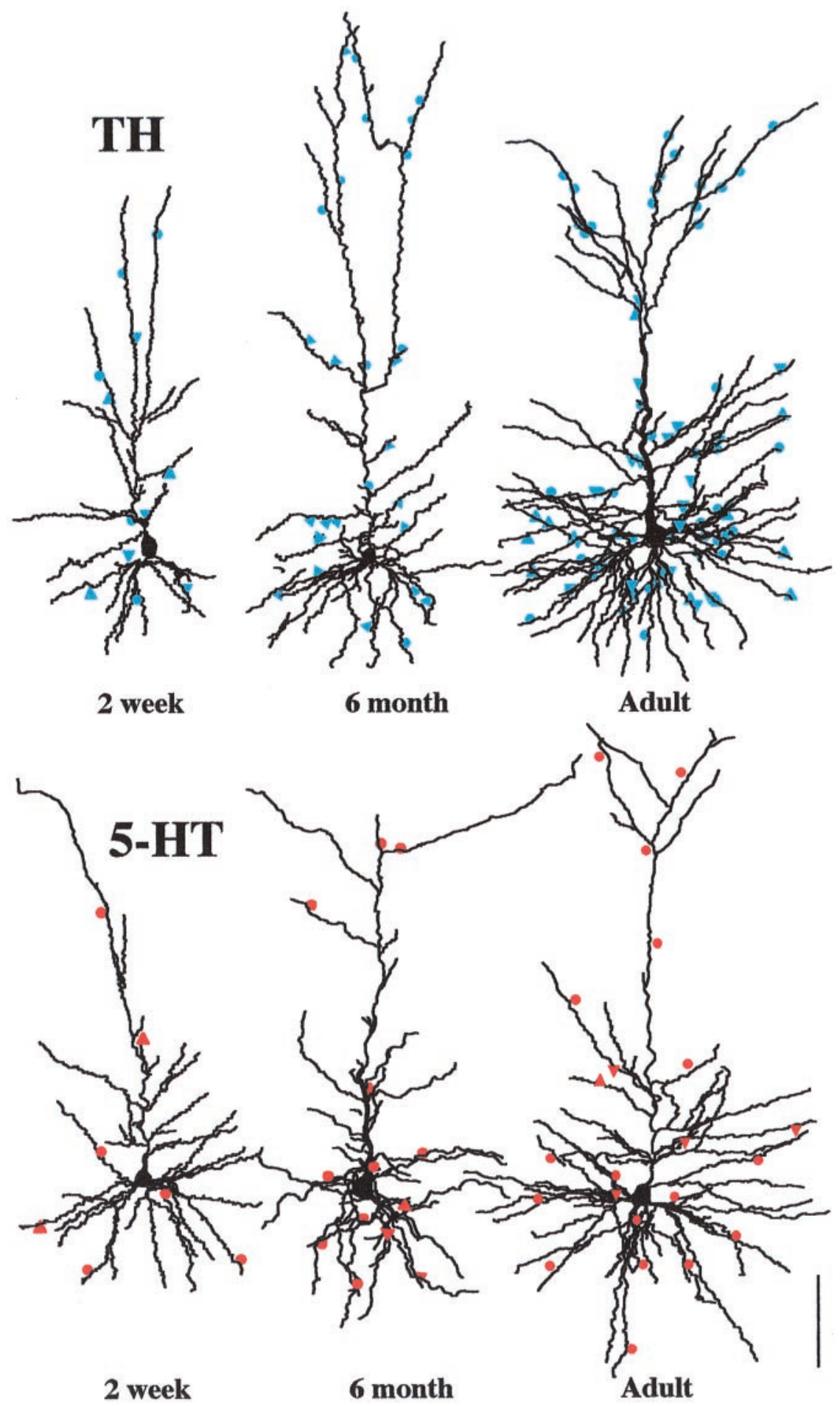

Adult

Adult
Figure 5. Neurolucida reconstructions of pyramidal cells with TH (blue) or 5-HT (red) appositions. There is a dramatic increase in TH apposition density over the age range studied, whereas 5-HT apposition density remains relatively constant. Triangles represent appositions to spines; circles represent appositions to dendritic shafts. Scale bar, $75 \mu \mathrm{m}$. geois et al., 1994). Density of asymmetric excitatory synapses reaches a peak between 2 and 4 months after birth and then declines gradually to adult levels. By contrast, density of inhibitory, symmetric synapses remains at a relatively constant level that is lower throughout postnatal development. A constant level of interneuron innervation by $\mathrm{TH}$ and 5-HT, and of pyramidal cell innervation by $5-\mathrm{HT}$, fits well with the expected curve for symmetric synapses. However, the increase in TH apposition density of pyramidal cells stands out from the typical pattern of synaptogenesis. The prolonged period of increasing $\mathrm{TH}$ innervation of pyramidal cells corresponds to the time period when a great number of asymmetric, glutamatergic synapses are being eliminated in frontal cortex (Bourgeois et al., 1994).

\section{Modulation of glutamate neurotransmission}

The cumulative increase in the dopaminergic innervation of pyramidal cells may have functional implications for the balance of excitation and inhibition in cortical circuitry, in particular, working memory circuits. In adult brain, electrophysiological studies have shown that both dopamine and 5-HT affect responsiveness of neurons to glutamate signaling. However, these two neuromodulators appear to modulate different aspects of glutamate transmission. In particular, dopamine appears to increase NMDA-gated currents in cortical pyramidal cells (Yang and Seamans, 1996; Zheng et al., 1999) (cf. Gulledge and Jaffe, 1998). Serotonin has been shown to greatly enhance AMPA transmission in these neu- 

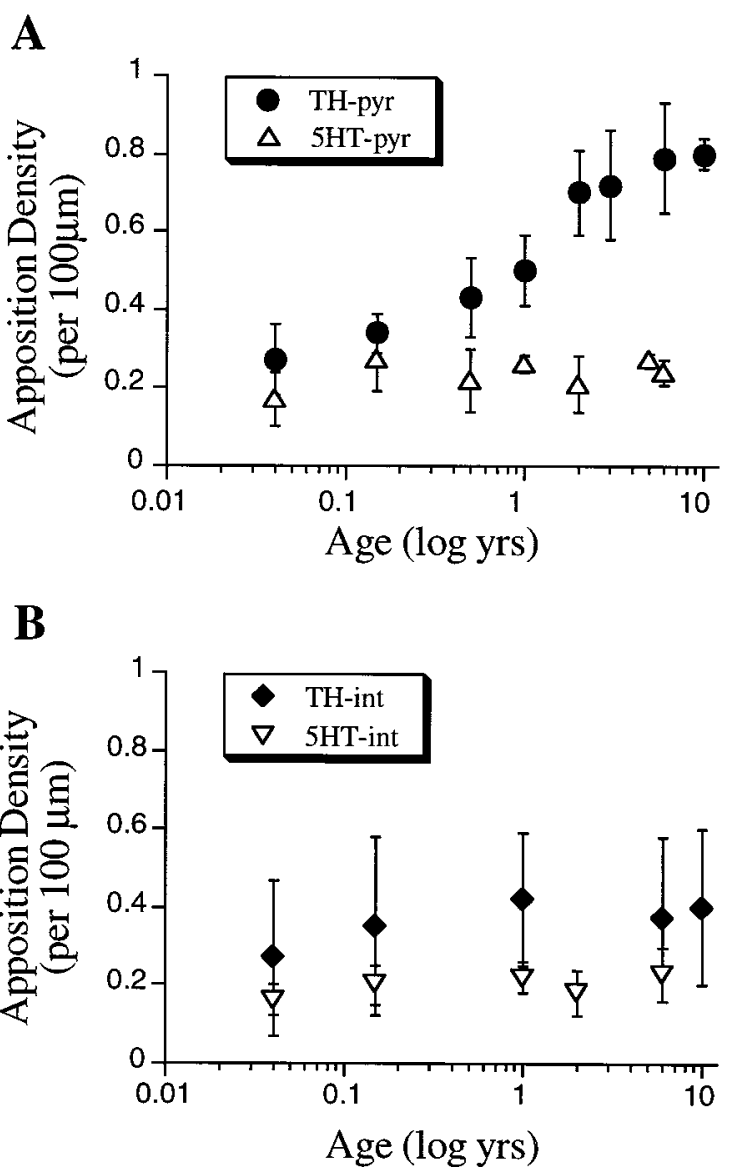

Figure 6. Mean TH versus 5-HT apposition density on pyramidal cells $(A)$ and interneurons $(B)$ for each group, plotted against age on a logarithmic scale.

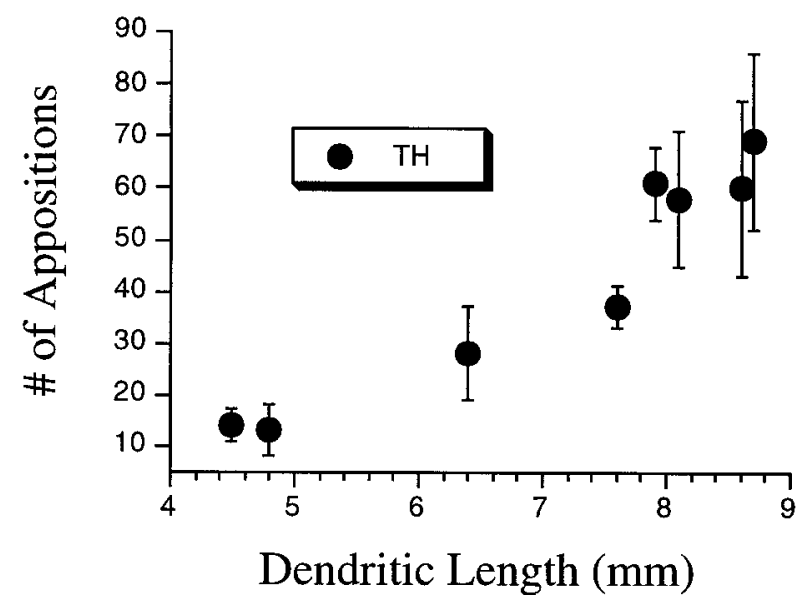

Figure 7. Correlation between pyramidal cell dendritic length and total number of TH appositions $(p=0.0002)$.

rons (Aghajanian and Marek, 1997). Indeed, stimulation of either dopamine or serotonin receptors can differently influence the spatial tuning of pyramidal cells and interneurons in prefrontal cortex of awake, behaving rhesus monkeys (Williams and Goldman-Rakic, 1995; Williams et al., 1998).

\section{Cognitive and clinical implications}

Temporal correlation between maturation of working memory and attainment of maximum $\mathrm{TH}$ apposition density on pyramidal cells poses the question about a causal relationship: is this increase in TH innervation density on pyramidal cells able to mediate condi- tions necessary for adult competency on tests of working memory? In adult monkey, performance on prefrontal tasks is highly vulnerable to dopamine depletion and relatively invulnerable to serotonin depletion (Brozoski et al., 1979). Several models have argued that the ability of dopamine to enhance NMDA signaling in adult pyramidal cells may be critical for delay period activity (Lisman et al., 1998; Wang, 1999). Infusion of NMDA antagonists, such as ketamine or phencyclidine, into the frontal cortex has been shown to impair performance on tasks of spatial working memory (Aura and Riekkinen, 1999) and delayed alternation (Verma and Moghaddam, 1996; Adams and Moghaddam, 1998). Cognitive impairments associated with NMDA blockade have been shown as likely to result from enhanced AMPA transmission (Moghaddam et al., 1997; Adams and Moghaddam, 1998). This evidence suggests that the balance of dopaminergic and serotoninergic modulation of glutamate transmission may be critical for adult performance on working memory tasks.

The postnatal changes in prefrontal circuitry observed in this study may have relevance to the radical change in the physiological response to ketamine anesthesia during adolescence. This anesthesia is no longer used in adults because it causes an "emergence" psychosis (Farber et al., 1999). In children, however, no such reaction exists (Farber et al., 1999). The developmental timing of the psychotogenicity of ketamine suggests that late-maturing systems, such as TH inputs to pyramidal cells, are finely tuned and critical for normal prefrontal function. The ability of ketamine to suppress NMDA transmission and increase AMPA transmission may upset a carefully regulated and complex equilibrium between dopamine and serotonergic modulation of pyramidal cell activity. Any of a number of conditions could similarly lead to imbalance of these systems. Further analysis of the interplay between dopamine and serotonin on neuronal signaling before, during, and after puberty may provide clues to mechanisms underlying the onset of schizophrenia in young adulthood.

\section{REFERENCES}

Adams B, Moghaddam B (1998) Corticolimbic dopamine neurotransmission is temporally dissociated from the cognitive and locomotor effects of phencyclidine. J Neurosci 18:5545-5554.

Aghajanian GK, Marek GJ (1997) Serotonin induces excitatory postsynaptic potentials in apical dendrites of neocortical pyramidal cells. Neuropharmacology 36:589-599.

Akil M, Lewis DA (1993) The dopaminergic innervation of monkey entorhinal cortex. Cereb Cortex 3:533-550.

Anderson SA, Classey JD, Conde F, Lund JS, Lewis DA (1995) Synchronous development of pyramidal neuron dendritic spines and parvalbumin-immunoreactive chandelier neuron axon terminals in layer III of monkey prefrontal cortex. Neuroscience 67:7-22.

Aura J, Riekkinen PJ (1999) Blockade of NMDA receptors located at the dorsomedial prefrontal cortex impairs spatial working memory in rats. NeuroReport 10:243-248.

Bourgeois JP, Goldman-Rakic PS, Rakic P (1994) Synaptogenesis in the prefrontal cortex of rhesus monkeys. Cereb Cortex 4:78-96.

Breier A (1995) Serotonin, schizophrenia, and antipsychotic drug action. Schizophr Res 14:187-202.

Brozoski T, Brown R, Rosvold H, Goldman P (1979) Cognitive deficit caused by regional depletion of dopamine in prefrontal cortex of rhesus monkeys. Science 205:929-932.

Buznikov GA (1984) The action of neurotransmitters and related substances on early embryogenesis. Pharmacol Ther 25:23-59.

Cases O, Vitalis T, Seif I, De Maeyer E, Sotelo C, Gaspar P (1996) Lack of barrels in the somatosensory cortex of monoamine oxidase A deficient mice: role of serotonin excess during the critical period. Neuron $16: 297-307$

Chubakov A, Gromova E, Konovalov G, Sarkisowa E, Chumasov E (1986) The effects of serotonin on the morpho-functional development of rat cerebral cortex in tissue culture. Brain Res 369:285-297.

Coyle JT, Molliver ME (1977) Major innervation of newborn rat cortex by monoaminergic neurons. Science 196:444-447.

Descarries L, Seguela P, Watkins C (1991) Nonjunctional relationships of monoamine axon terminals in the cerebral cortex of adult rat. In: Volume transmission in the brain (Fuxe K, Agnati L, eds), pp 53-62. New York: Raven.

Diamond A, Goldman-Rakic PS (1989) Comparison of human infants and rhesus monkeys on Piaget's AB task: evidence for dependence on dorsolateral prefrontal cortex. Exp Brain Res 74:24-40.

Farber N, Newcomer J, Olney J (1999) Glycine agonists: What can they teach us about schizophrenia? Arch Gen Psychiatry 56:13-17. 
Goldman-Rakic P, Brown R (1982) Postnatal development of monoamine content and synthesis in the cerebral cortex of rhesus monkeys. Dev Brain Res 4:339-349.

Goldman-Rakic PS (1987) Development of cortical circuitry and cognitive function. Child Dev 58:601-622.

Goldman-Rakic PS, Leranth C, Williams SM, Mons N, Geffard M (1989) Dopamine synaptic complex with pyramidal neurons in primate cerebral cortex. Proc Natl Acad Sci USA 86:9015-9019.

Gouzoulis-Mayfrank E, Schreckenberger M, Sabri O, Arning C, Thelen B, Spitzer M, Kovar K-A, Hermle L, Bull U, Sass H (1999) Neurometabolic effects of psilocybin, 3,4-methylenedioxyethylamphetamine (MDE) and d-methamphetamine in healthy volunteers. Neuropsychopharmacology 20:565-581.

Gu Q, Singer W (1995) Involvement of serotonin in developmental plasticity of kitten visual cortex. Eur J Neurosci 7:1146-1153.

Gulledge AT, Jaffe DB (1998) Dopamine decreases the excitability of layer $\mathrm{V}$ pyramidal cells in the rat prefrontal cortex. $\mathrm{J}$ Neurosci 18:9139-9151.

Jakab RL, Goldman-Rakic PS (1998) 5-Hydroxytryptamine ${ }_{2 A}$ serotonin receptors in the primate cerebral cortex: possible site of action of hallucinogenic and antipsychotic drugs in pyramidal cell apical dendrites. Proc Natl Acad Sci USA 95:735-740.

Kalsbeek A, Matthijssen MA, Uylings HB (1989) Morphometric analysis of prefrontal cortical development following neonatal lesioning of the dopaminergic mesocortical projection. Exp Brain Res 78:279-289.

Koenderink MJT, Uylings HBM, Mrzljak L (1994) Postnatal maturation of the layer III pyramidal neurons in the human prefrontal cortex: a quantitative Golgi study. Brain Res 653:173-182.

Krimer LS, Jakab RL, Goldman-Rakic PS (1997) Quantitative threedimensional analysis of the catecholaminergic innervation of identified neurons in the macaque prefrontal cortex. J Neurosci 17:7450-7461.

Lauder JM, Bloom FE (1974) Ontogeny of monoamine neurons in the locus coeruleus, Raphe nuclei, and substantia nigra of the rat. I. Cell differentiation. J Comp Neurol 155:469-481.

Levitt P, Harvey JA, Friedman E, Simansky K, Murphy EH (1997) New evidence for neurotransmitter influences on brain development. Trends Neurosci 20:269-274.

Lewis D, Hayes T, Lund J, Oeth K (1992) Dopamine and the neural circuitry of primate prefrontal cortex: implications for schizophrenia research. Neuropsychopharmacology 6:127-134.

Lidow MS, Goldman-Rakic PS, Rakic P (1991) Synchronized overproduction of neurotransmitter receptors in diverse regions of the primate cerebral cortex. Proc Natl Acad Sci USA 88:10218-10221.

Lieberman JA (1999) Pathophysiologic mechanisms in the pathogenesis and clinical course of schizophrenia. J Clin Psychiatry 60[Suppl 12]:9-12.

Lisman JE, Fellous JM, Wang XJ (1998) A role for NMDA-receptor channels in working memory. Nat Neurosci 1:273-275.

Mattson MP (1988) Neurotransmitters in the regulation of neuronal cytoarchitecture. Brain Res 472:179-212.

Meier E, Hertz L, Schousboe A (1991) Neurotransmitters as developmental signals. Neurochem Int 19:1-15.

Moghaddam B, Adams B, Verma A, Daly D (1997) Activation of glutamatergic neurotransmission by ketamine: a novel step in the pathway from NMDA receptor blockade to dopaminergic and cognitive disruptions associated with the prefrontal cortex. J Neurosci 17:2921-2927.

Noack HJ, Lewis DA (1989) Antibodies directed against tyrosine hydroxylase differentially recognize noradrenergic axons in monkey neocortex. Brain Res 500:313-324.
Rakic P, Bourgeois JP, Eckenhoff MF, Zecevic N, Goldman-Rakic PS (1986) Concurrent overproduction of synapses in diverse regions of the primate cerebral cortex. Science 232:232-235.

Rosenberg D, Lewis D (1995) Postnatal maturation of the dopaminergic innervation of monkey prefrontal cortices: a tyrosine hydroxylase immunohistochemical analysis. J Comp Neurol 358:383-400.

Sawaguchi T, Matsumura M, Kubota K (1990) Catecholaminergic effects on neuronal activity related to a delayed response task in monkey prefrontal cortex. J Neurophysiol 63:1385-1400.

Sesack S, Hawrylak V, Melchitzky D, Lewis D (1998) Dopamine innervation of a subclass of local circuit neurons in monkey prefrontal cortex: ultrastructural analysis of tyrosine hydroxylase and parvalbumin immunoreactive structures. Cereb Cortex 8:614-622.

Smiley J, Goldman-Rakic P (1993) Heterogeneous targets of dopamine synapses in monkey prefrontal cortex demonstrated by serial section electron microscopy: a laminar analysis using the silver-enhanced diaminobenzidene sulfide (SEDS) immunolabeling technique. Cereb Cortex 3:223-238.

Smiley J, Goldman-Rakic P (1996) Serotonergic axons in monkey prefrontal cerebral cortex synapse predominantly on interneurons as demonstrated by serial section electron microscopy. J Comp Neurol 367:431-443.

Verma A, Moghaddam B (1996) NMDA receptor antagonists impair prefrontal cortex function as assessed via spatial delayed alternation performance in rats: modulation by dopamine. J Neurosci 16:373-379.

Verney C, Milosevic A, Alvarez C, Berger B (1993) Immunocytochemical evidence of well-developed dopaminergic and noradrenergic innervations in the frontal cerebral cortex of human fetuses at midgestation. J Comp Neurol 336:331-344.

Vollenweider FX, Vollenweider-Scherpenhuyzen MFI, Babler A, Vogel H, Hell D (1998) Psilocybin induces schizophrenia-like psychosis in humans via a serotonin-2 agonist action. NeuroReport 9:3897-3902.

Wang X (1999) Synaptic basis of cortical persistent activity: the importance of NMDA receptors to working memory. J Neurosci 19:9587-9603.

Williams GV, Goldman-Rakic PS (1995) Modulation of memory fields by dopamine D1 receptors in prefrontal cortex. Nature 376:572-575.

Williams GV, Rao S, Goldman-Rakic PS (1998) Serotonin 2 receptor modulation of mnemonic coding in prefrontal cortex. Biol Psychiatry 43:S7.

Williams S, Goldman-Rakic P (1993) Characterization of the dopaminergic innervation of the primate frontal cortex using a dopamine-specific antibody. Cereb Cortex 3:199-222.

Wilson MA, Ricaurte GA, Molliver ME (1989) Distinct morphologic classes of serotonergic axons in primates exhibit differential vulnerability to the psychotropic drug 3,4-methylenedioxymethamphetamine. Neuroscience 28:121-137.

Yang CR, Seamans JK (1996) Dopamine D1 receptor actions in layers $\mathrm{V}-\mathrm{VI}$ rat prefrontal cortex neurons in vitro: modulation of dendriticsomatic signal integration. J Neurosci 16:1922-1935.

Zheng P, Zhang X-X, Bunney B, Shi W-X (1999) Opposite modulation of cortical $N$-methyl-D-aspartate receptor-mediated responses by low and high concentrations of dopamine. Neuroscience 91:527-535.

Zoli M, Agnati L (1996) Wiring and volume transmission in the central nervous system: the concept of closed and open synapses. Prog Neurobiol 49:363-380. 